\title{
Lexical Features and Translation of English for Psychology ${ }^{*}$
}

\author{
Tianyu Wang \\ School of Foreign Languages, University of Shanghai for Science and Technology, Shanghai 200093 \\ Gaofeng Yu \\ School of Foreign Languages, University of Shanghai for Science and Technology, Shanghai 200093
}

\begin{abstract}
English for Psychology has its particular lexical features, such as lots of specialized common words, abbreviations, high requirements for professional knowledge. This paper, by way of examples, analyses these lexical features and offers the related translation strategies.
\end{abstract}

Index Terms — English for Psychology, lexical features, translation strategies

\section{INTRODUCTION}

Psychology is a science that studies human psychological phenomena, mental function and behavior. In today's society, people's life and survival pressures are increasing with the rapid development of economy, science and technology, so psychology plays an important role in studying people's production and life. In 1879, Wihelm Wundt established the first psychology laboratory at the University of Leipzig, Germany, marking the birth of psychology. However, the development of psychology in China was very tortuous. Until 1917, Cai Yuanpei established the first psychology laboratory in Peking University, which marked the spread of psychology in China. Now, even though more and more attention has been paid on psychology studies and significant progress has been achieved at home, it still has not established a complete psychological system.

Nowadays, the development of the times and society has made the application of psychology more and more extensive at home. However, we still need to realize that compared with Western countries, the development of psychology in China is still far from mature, we still need to learn from foreign literatures and predecessors' researches. Moreover, English for psychology is characterized by long sentences, multi-professional vocabularies, and is always complicated and difficult to analyze. It is still a big difficulty to read foreign literatures accurately. Translation, as a practical activity of bilingual conversion, bears the responsibility of promoting cultural integration, exchange of ideas and common progress in science and technology between different countries. Therefore, only by mastering the professional knowledge and lexical features of English for psychology can we accurately understand and translate the meaning of the original text, and be in line with world psychology.

\section{TRansLation of ENGLish Vocabulary of PSychology}

\section{A. Translation of Psychological Terminology and Psychologists}

Due to the differences in social culture, some words in English have not be explained by foreign authors, but rather be left in the basket, which may have an effect on our understanding. For the science of psychology, it is a science emerging from the West. It was introduced to China at the end of the 19th century. There have been several different translations: "Psychology", "Soulology", "Psychology", etc. The English word "Psychology", in terms of its literal meaning, is originally related to "psyche", "soul", "mind" and "consciousness" in Chinese. It is related, but it does not directly relate to the "heart" corresponding to our "temperament" in China. However, "心理学" is used to translate and introduce the "Psychology" in the West. Shen Heyong (1996) argues that this is actually a combination of the "Mind" in the West and the "Heart" in China, and Psychology in Chinese culture has been deeply included. Another example is Gestalt Psychology, which is a branch of psychology that is independent from psychology. Shen Heyong (1996) argues The more common translation of “Gestalt Psychology” is “格式塔心理学”, which was originally proposed by Xiao Xiaorong. But the translation version of "完形心理学"also exists. Obviously, different translation versions of the same term can cause confusions and misunderstandings of psychological concepts and terminology for readers, and even cause errors in understanding and translation.

For the translation of the name of the psychologists, the first one to say is W.M.Wundt, the father of psychology. As the founder of psychology, he established the world's first psychology laboratory at the University of Leipzig in

\footnotetext{
* The paper is projected by 2017 Humanities and Social Sciences Cultivation Fund of University of Shanghai for Science and Technology. (Project No.: SK17ZD05)
} 
Germany in 1879 and laid the foundation for psychology as a science. However, there are still two different translations for his name. Gao Juefu translated it as "冯特", and Tang Cheng translated it into "冯德". Another example, the founder of Gestalt Psychology, Max Wertheimer, there are several different translations for his name. Gao Juefu translated it as “惠太海默”, Tang Cheng translated it as “魏特默”, and Lin Fang translated it as "韦特海默尔".Moreover, Kurt Lewin, who had a profound influence on the development of Gestalt psychology and contemporary social psychology, there are also several different translations of his name. The translation of Gao Juefu is "勒温", Lin Fang's translation is "莱温" and Lu Yin's translation is "莱因", etc. In addition, for the child psychologist Jean Piaget, who put forward the significant cognitive development theory, although "皮亚杰" has become the most popular translation , but also some people translate his name as "皮阿热." The names of these psychologists may be distinguishable for readers of psychology, but they are difficult for non-psychology readers. They cannot distinguish whether “冯特” and “冯德” is the same person，“皮亚杰” and “皮阿热” is the same. Once the cognitive deviation occurs, it will also cause errors in the understanding of the psychological text.

\section{B. Specialized Translation of Common Vocabulary}

Chen Ling (2008) argues English can be generally divided into English for General Purposes (EGP) and English for special purposes (ESP), and vocabulary is one of the main differences between the two, and the polysemy is a major difficulty in learning English for specialized purposes. In English for psychology, many common vocabularies from English are given special meanings. These words often have several different meanings, also known as polysemous words. The same vocabulary is quite different in general application and psychology applications. For example, the general translation of "tolerance" is "公差, 忍受力, 耐受性" and it is translated as "抗药性" in psychology. The ordinary translation of "withdrawal" is "撤退, 撤回", and in psychology it is translated as "戒断". The ordinary translation of "complex" is "复杂的, 合成的", and it is translated as "情节" in psychology. The ordinary translation of "insight" is "洞察力", and in psychology it is translated as "顿悟". The ordinary translation of "rehearsal" is "排演, 排 练" and it is translated as "复诵" in psychology. Therefore, Tian Chuanmao (2016) argues that the translator should be good at identifying the ordinary meaning and professional technical meaning of the words, and can not confuse one with another.

\section{Translation of Professional Vocabularies Consisting of Affixes and Roots}

Most of the scientific vocabulary is composed of roots, prefixes and suffixes derived from Latin or Greek. This is a major feature of scientific vocabulary in terms of etymology. A large number of vocabularies in English for psychology are formed by the combination of derivative affixes or roots and ordinary vocabularies. Affixes and roots are essential elements that constitute an English vocabulary for psychology, which has strong adhesion, great flexibility, and a strong and extremely versatile ability. Based on these characteristics, there are some regular rules for translators to translate professional English for psychology. For example, psycho-, its meaning is "心理的", which is used as a prefix and combined with different common nouns to generate the following psychological professional vocabularies: (1) psycho-dynamics (精神动力学) (2) psychoanalysis (心理分析) (3) psychotherapy (心理疗法) (4) psychologist (心理 学家) (5) psycho-physics (心理物理学). And bio-, of which the meaning is "生理的", as a prefix, it is combined with different common nouns, it can generate the following psychological professional vocabularies: (1) biofeedback (生理 反馈) (2) bio-clock (生物钟) (3) bionergy (生命力) (4) biophilia (生物自卫本能) (5) bioreaction (生理反应). Another example, re-, its meaning is "再, 重新". As a prefix, it is combined with different common nouns to generate the following psychological professional vocabularies : (1) recognition (再认) (2) relarning (再学习) (3) recall (回忆) (4) relapse (复吸). In addition, such as the root -ism, its meaning is "论, 主义", and there are the psychology vocabularies derived from it: (1) behaviorism (行为主义) (2) determinism (决定论) (3) cognitivism (认知论) (4) nativism (先天论) (5) empiricism (经验论). These words are derived from the combination of derived affixes or roots and different common vocabularies, and they always have a special professional meaning.

\section{Translation of Abbreviations in Psychology English}

In recent years, the use of abbreviations has become more widespread, the number of Chinese abbreviations is small, the meaning is clear, and the use is relatively formal. In contrast, the number of English abbreviations is huge, and it is still increasing. If you are not careful enough in the process of use, it is easy to misinterpret the meaning of the original text. As a science, rigor is indispensable for psychology, and there are also a large number of abbreviations in English for psychology. Therefore, it is especially important to correctly understand the abbreviations when reading psychology English literatures. For example: (1) CBT, it means Cognition Behavior Therapy in psychology, rather than Chicago Board of Trade (2) TOT, it refers to Tip of Tongue, not Transfer of Technology (3) GSR, it is the Galvanic Skin Response in psychology, not the General Staff Requirement (4) OCD, it is Obsessive Compulsive Disorder, not Office Of Civil Defense or Office for Child Development (5) PTSD, it is Post Traumatic Stress Disorder, which is a widely used psychology abbreviation because the symptom always occurs to people in modern life, and this abbreviation is frequently occurs in a large number of psychological English reading materials. Therefore, it is very important to 
understand the professional knowledge related to psychology. Only by understanding and mastering the professional knowledge of psychology and lexical features of English for psychology can we accurately and correctly translate the materials. At the same time, translators can improve their productivity based on accurate translation.

\section{Vocabulary Translation StRategies of English For Psychology}

\section{A. Accumulating Professional Knowledge of Psychology in Practice}

Liang Bo (2017) argues that the translation of any terminology requires the translator to have a broad background of professional knowledge. The translation of psychology terminology is no exception. As a science, psychology is closely related to sciences such as physiology, physics, natural sciences, neuroscience, medicine, etc., and the knowledge involved is also very extensive. It requires translators to have extensive and profound professional knowledge, further to understand and translate the original text based on professional knowledge. In addition, based on the knowledge of psychology, translators should do more translation practice. Only by practicing can they accumulate translation experience and reflect the content of the source language text.

Example 1: Someone's nature is their character, which they show by the way they behave.

Translation 1: 一个人的本质就是他们行为方式表现出的性格。

Translation 2: 一个人的行为方式体现出他们的性格。

Comparing the two translations in Example 1, we can obviously see that the translation 1 does not accurately translate the meaning of the word "nature" in the sentence. The translation is very sturdy and difficult to understand. In translation 2, the "nature" is accurately translated into "性格", and the "character" also means t“性格”, so the translation is consistent. After combining the two translations and adjusting the translation order, as shown in the translation 2, the meaning of the "nature" in psychology is correctly reflected.

Example 2: Yet scientists and laymen alike still spend too much time and effort trying to quantify the relative importance of nature and nurture.

Translation: 但还是有一些科学家和非专业人员花大量时间和努力, 试图量化先天与后天之间的相对重要性。

The "nature" in Example 2 is translated as “先天”. When the word "nature" and "nurture” appear in a psychology article at the same time, the two words correspond to each other and are translated as “先天” and “后天”, and later extended to “先天遗传说” and “后天培养说”. The word “nature” originally means "自然" in the natural sciences, "本 质, 性质" in law, and often refers to "天性, 性格, 先天" in psychology. When reading psychology materials, you should understand the original meaning accurately and translate accurately, moreover, the accumulation of professional knowledge is also essential.

Such as the word "stage", it contains multiple meanings just as a noun, "阶段, 时期, 舞台, 戏剧".

For example: Usually, the performance of actors is on the stage.

This sentence is very simple, and can be translated as: 演员的表演一般在舞台上展开。 In this sentence, because there are two words "actor" and "performance" in the sentence, the deep meaning of the stage is also coming out, obviously should be translated into “舞台”. However, in psychology, there are two professional vocabularies, "preoperational stage" and "sensorimotor stage". These two words are relatively simple, and are respectively translated into "远思时期"and "感觉动作期", at this time, the word "stage" represents "时期, 阶段". These two words represent the development of cognitive stages proposed by psychologist Piaget through observation and research on children's behavior. He divides the cognitive development of children into four stages and the preoperational stage and sensorimotor stage are the first two phases of these four. Another example is “ethology”, which means “动物行为学” in animal science, and “习性学” in psychology; and the phrase "peg word”, “peg” means “钩”, word means “文字”, and the phrase means "字钩法" in psychology; "coding specificity" means "登录特殊性" instead of "编码特殊性"; "sex typing" means "性别配合" instead of "性别输入"; "autoshaping" means "性别塑造" instead of “自动形成”. The main reason for the inaccurate translation of these words is that translators always rely solely on the relevant terms of the dictionary for translation, lacking relevant professional knowledge, and cannot choose the correct meaning. According to the above terminology, in order to accurately translate these words, translators must have a certain understanding of the background knowledge in related fields. Fully consider the context of the context, and then translate the terminology in conjunction with the expression habits of the psychology profession to avoid mistranslation. Qiao Junkai (2016) argues that attention should be paid to the use of standardized terminology in translation to maintain the consistency of terminology.

\section{B. Translation of English for Psychology Needs Scientific and Strict Attitude}

Psychology is not only a theoretical science, but also an applied science. This feature requires translators to have a rigorous and scientific translation attitude. They should not rely solely on the dictionary or their own understanding of related terms, instead, translators should refer to the literatures, select the exact meaning, and make sure the final translation is correct.

Example 3: Freud (弗洛伊德) exposes and releases the nosogenetic memories which repressed into the 
unconsciousness by Talking Cures.

Translation 1: 弗洛伊德通过谈话疗法来揭发并解放被患者压抑进无意识中的致病记忆。

Translation 2: 弗洛伊德通过谈话疗法来发掘并释放被患者压抑进潜意识中的致病记忆。

In Example 3, the main difference between the two translations is the meaning of "unconsciousness". In ordinary text, the prefix "un-" often means "none, no", but in psychology, "unconsciousness" represents sub-consciousness (潜意识), not unconsciousness (无意识). These two are far apart in meaning. There is an obvious mistake in translation 1, that is taken for granted, neglecting the meaning of professional vocabulary, and the self-understanding leads to translation errors. In addition, the translations of "expose" and "release" are also improved in translation 2, making the translation more contextual and more rigorous and accurate.

Example 4: Generally speaking, there are five stages of grief in psychology, including denial, anger, bargaining, depression and acceptance.

Translation 1:总体而言，在心理学上悲伤有五个舞台,包括否认，愤怒，协商，绝望和接受。

Translation 2: 总体而言, 在心理学上悲伤有五个阶段, 包括失落, 愤怒, 迷茫, 消极和接受。

In Example 4, the main difference between translation 1 and translation 2 is reflected in the translation of "stage, denial, bargaining and depression". In translation 1, the "stage" is translated into "舞台", which is obviously wrong. The surface meaning of "stage" is "舞台", but it is always translated as "时期, 阶段", and in psychology, the word "stage" means "阶段" (the word has been mentioned in this paper). In addition, the translations of "denial, bargaining and depression" in translation 1 also just take the surface meaning, instead of making in-depth research and thinking on sentences. In psychology, these words have special meanings, indicating three stages of "loss, confusion and negative", as shown in translation 2. The reason for these translation errors is that the translator does not have a rigorous scientific attitude to verify the in-depth meaning of these words in the psychological text, but to take the surface meaning. Therefore, when translating the psychological text, the scientific rigor attitude is an important criterion for ensuring that the translation is accurate. When translating these vocabularies with shallow and deep meanings, the translator should maintain the original text features, and the choices of words should be accurate when translating to avoid the ambiguity of the translations.

\section{Translation Methods Commonly Used in Psychological Text Translation}

Translation methods commonly used by translators include literal translation and free translation. And $\mathrm{n}$ the translation process of psychological texts, professional translators usually use the method of literal translation. The so-called "literal translation" means that the translation not only conveys the content of the original text, but also preserves the style and form of the original text as completely as possible. When the difference between the sentence and the vocabulary of the original language and the target language is not large, the translation can be basically carried out in the form of the original text. Because psychology texts are objective, clear in concept, and rarely emotional, so literal translation is more likely to be used in the translation of psychological texts. In addition, other methods commonly used by professional translators include Omission and Amplification. The so-called Amplification is to add the necessary words, phrases, clauses, or complete sentences on the basis of the original text, so that the translation conforms to the translation habits in grammar and language form. Furthermore, Qiao Junkai (2016) argues that in terms of cultural background, word association, the translation should be equal to the original text from three aspects including content, form and spirit.

For example, "elaboration" expresses “精致化处理” in psychology, rather than “精致化”, and the word “处理” is added here. The word "elaboration" refers to the processing of the connotation and extension of concepts in psychology as much as possible, which is a process. The phrase "method of location", namely "method of loci", which means "位置记忆法" instead of "位置法", and the word "记忆" is added. It is a kind of traditional memory method. For another translation method, Omission, as its name suggests, it is a translation strategy corresponding to Amplification. Jia Wenbo (2007) argues that delete words that do not conform to the target language habits, language habits and expressions to avoid the cumbersome translation.

\section{CONCLUSiOnS}

With the development of society and the increasing pressure of life, human beings have deepened their understanding of themselves, and various psychological problems have gradually emerged. Psychology plays an important role in the study of people's production and life. At the same time, the translation of psychology professional English is crucial to the development of psychology in China. The translation of English for Psychology is not only a feature of scientific English, but also has its own particularity. Translators should try to use standardized professional terms when translating, not only should adhere to the scientific and rigorous attitude, but also need to improve their understanding of professional knowledge of psychology, do practice under the premise of proficiency in professional knowledge, and explore in practice. Besides, translators should summarize the characteristics of translation of English for psychology in practice to avoid translation errors, ensure accurate understanding of the original text, correctly translate texts, and promote the integration of Chinese psychology and world psychology. 


\section{REFERENCES}

[1] Chen Ling, Xiao Nan, Xiao Wenke. (2008). Study on the lexical features of business English--a polysemous phenomenon. China Electric Power Education, 3, 189-191.

[2] Jia Wenbo. (2007). The Enlightenment of Functional Translation Theory to Applied Translation, Shanghai Journal of Translation, 2, 9-14.

[3] Liang Bo. (2017). The terminology of photographic texts and English-Chinese translation. Chinese Science and Technology Translators Journal, 1, 1-3.

[4] Qiao Junkai, Yu Gaofeng. (2016). The lexical features and translation of the manual for the use of technology products - take SKF products as an example. Chinese Science and Technology Translators Journal, 29, 36-38.

[5] Shen Heyong. (1996). The Standardization of Psychological Terminology Translation. Acta Psychologica Sinica, 28, 425-430.

[6] Tian Chuanmao. (2016). The Trap in the Translation of Police Science and Technology-Taking the Chinese Translation of Petroleum Machinery as an Example. Chinese Science \& Technology Translators Journal, 9, 58-59.

Tianyu Wang was born in Jiangsu province, China in 1995.She is currently a postgraduate in the College of Foreign Languages, University of Shanghai for Science and Technology, Shanghai, China. Her major is Master of Translation and Interpretation.

Gaofeng Yu was born in Henan province, China in 1959. He is currently an associate professor, M.A., College of Foreign Languages, University of Shanghai for Science and Technology, Shanghai, China. His research interests include translation theory and practice. 